\title{
WITHDRAWN: Commentary: Unicorns and leprechauns
}

\author{
Christopher E. Mascio, MD
}

Division of Pediatric Cardiothoracic Surgery, Department of Surgery, Children's Hospital of Philadelphia, Philadelphia, $\mathrm{Pa}$

Perelman School of Medicine, University of Pennsylvania, Philadelphia, Pa

The Publisher regrets that this article is an accidental duplication of an article that has already been published, https://doi.org/10.1016/j.jtcvs.2019.12.017. The duplicate article has therefore been withdrawn.

The full Elsevier Policy on Article Withdrawal can be found at https://www.elsevier.com/about/our-busi ness/policies/article-withdrawal 